\title{
Immunization with a suicidal DNA vaccine expressing the E glycoprotein protects ducklings against duck Tembusu virus
}

Jingyu Tang ${ }^{1,2+}$, Zhuangli Bi ${ }^{1,2+}$, Mingyang Ding ${ }^{2 \dagger}$, Dongdong Yin ${ }^{1,3}$, Jie Zhu², Li Zhang ${ }^{1,2}$, Qiuhong Miao ${ }^{2}$, Yingqi Zhu ${ }^{1,2}$, Guijun Wang ${ }^{1,3^{*}}$ and Guangqing Liu ${ }^{2^{*}}$

\begin{abstract}
Backgroud: Duck Tembusu virus (DTMUV), a pathogenic flavivirus, emerged in China since 2010 and causing huge economic loss in the Chinese poultry industry. Although several vaccines have been reported to control DTMUV disease, few effective vaccines are available and new outbreaks were continuously reported. Thus, it is urgently to develop a new effective vaccine for prevention of this disease.

Methods: In this study, a suicidal DNA vaccine based on a Semliki Forest virus (SFV) replicon and DTMUV E glycoprotein gene was constructed and the efficacy of this new vaccine was assessed according to humoral and cell-mediated immune responses as well as protection against the DTMUV challenge in ducklings.

Results: Our results showed that the recombinant SFV replicon highly expressed E glycoprotein in DEF cells. After intramuscular injection of this new DNA vaccine in ducklings, robust humoral and cellular immune responses were observed in all immunized ducklings. Moreover, all ducklings were protected against challenge with the virulent DTMUV AH-F10 strain.
\end{abstract}

Conclusions: In conclusion, we demonstrate that this suicidal DNA vaccine is a promising candidate facilitating the prevention of DTMUV infection.

Keywords: Suicidal DNA vaccine, Duck tembusu virus, E glycoprotein, Ducklings

\section{Background}

Since April 2010, outbreaks of infectious disease in ducks resulting from duck Tembusu virus (DTMUV) have reported throughout the main duck-producing regions of China [1,2]. Ducks infected with DTMUV often develop high fever, diarrhea, and weight loss, and exhibit retarded growth and decreased egg-laying [1-3]. And the morbidity rate of DTMUV disease can reach up to $90 \%$, as well as the mortality rates vary from 5 to $30 \%$ [1, $2,4,5]$. In addition to China, a similar DTMUV disease has also emerged in Thailand and Malaysia in 2012 [6,

\footnotetext{
* Correspondence: wgj@ahau.edu.cn; wangvet@yahoo.com; liugq@shvri.ac.cn †Jingyu Tang, Zhuangli Bi and Mingyang Ding contributed equally to this work.

${ }^{1}$ College of Animal Science and Technology, Anhui Agricultural University, Hefei 230036, China

${ }^{2}$ Shanghai Veterinary Research Institute, Chinese Academy of Agricultural Sciences, No. 518 Ziyue Rd, Shanghai 200241, China

Full list of author information is available at the end of the article
}

7]. Due to the highly contagious nature of this virus, DTMUV has resulted in huge economic losses in the duck industry. Notably, it has also been reported that DTMUV has a wide host spectrum such as ducks, geese [8], chickens [9] and sparrows [10]. It is noteworthy that Tang et al. reported DTMUV also caused human infection and may be a zoonotic pathogen in China [11]. Thus, a safe and efficient vaccine be developed to prevent this disease is essential.

To date, two types of immunization strategies have been adopted to protect against DTMUV infection. The first involves the vaccination of breeder ducks before they lay eggs, which can result in protection of the offspring via maternally-derived antibodies present in the egg yolk. The second strategy involves the vaccination of susceptible ducklings. While an efficient live attenuated candidate vaccine against DTMUV has been reported [12], this type of vaccine is inefficient for differentiating infected from

(C) The Author(s). 2018 Open Access This article is distributed under the terms of the Creative Commons Attribution 4.0 International License (http://creativecommons.org/licenses/by/4.0/), which permits unrestricted use, distribution, and 
vaccinated animals (DIVA) and the live attenuated vaccine may hold potential virulence reversion [13, 14]. Moreover, the production of this vaccine is costly and labor-intensive. Therefore, a more cost-effective and safe DTMUV vaccine is urgently needed to protect the duck industry, and to facilitate sero-surveillance and sero-monitoring.

In recent years, suicidal DNA vaccines based on alphavirus replicon vector systems (particularly that of Semliki Forest virus, SFV) have been exploited for gene therapy and vaccine development [15-17]. Indeed, researchers have successfully utilized suicidal DNA vaccines to target a variety of viruses, including those causing influenza in humans [18], peste des petits ruminants virus [19], porcine reproductive and respiratory syndrome virus [20], foot-and-mouth disease [21], and classical swine fever [22]. Suicidal DNA vaccines have many advantages as a strategy for antiviral vaccine development. For example, suicidal DNA vaccines can induce high-level humoral and cell-mediated immunity against various antigens [23-25], and can be used to overcome immunological tolerance by activating innate antiviral pathways [26]. Moreover, efficient immune responses can be obtained with a small amount of plasmid since its self-replicating ability [23], and such suicidal DNA vaccines can also be used for differentiating infected from vaccinated animals (DIVA) [27]. Notably, such vaccines are easy to construct, and have been shown to exhibit efficient expression of interest gene in vitro and to induce humoral and cellular immune responses in vivo, making them an appealing tool for the development of a vaccine against viral diseases [23, 25, 28]. Most importantly, the apoptotic mechanism of these vaccines eliminates the risk of integration of viral DNA into the host cell genome, which is useful to biosafety [29]. All these advantages make suicidal DNA vaccine an outstanding strategy to control DTMUV infection.

DTMUV is a member of genus Flavivirus, in family Flaviviridea, that harbors a single-stranded positive-sense RNA genome comprised of a single large open reading frame (ORF), approximately 10,990-nucleotides in size, which encodes three structural proteins including capsid protein $(\mathrm{C})$, pre-membrane (prM) and envelope (E) glycoprotein and seven nonstructural (NS) proteins including NS1, NS2A, NS2B, NS3, NS4A, NS4B, and NS5 [30, 31]. $\mathrm{E}$ glycoprotein is embedded at the viral surface and was shown to be the major target of neutralizing antibodies that clear Flavivirus infections [32]. Moreover, previous studies of flaviviruses such as West Nile virus [33], Japanese encephalitis virus [34], and tick-borne encephalitis virus [35] indicated that the gene encoding this $E$ protein might be useful for vaccine development. For example, Wang et al. reported that mice immunized with the recombinant $\mathrm{E}$ protein which was expressed and purified form Escherichia coli developed E protein antibodies and were protected from infection with West Nile virus [36]. A previous study showed that immunization with pseudotype baculovirus expressing E protein of Japanese encephalitis virus in mice could elicit high levels of protective immunity [37]. Similarly, Raviprakash et al. found the candidate DNA vaccine expressing $\mathrm{E}$ protein of dengue virus type 1 produced dengue- 1 specific antibodies that were both neutralizing and long lasting in mice [38]. All these previous studies suggest that the E glycoprotein could also be a good vaccine candidate against the DTMUV infection.

In this study, we constructed a suicidal DNA vaccine expressing the E glycoprotein of DTMUV. The efficacy of this potential vaccine was further evaluated according to humoral and cell-mediated immune responses as well as protection against the DTMUV challenge in ducklings.

\section{Methods \\ Cell culture and virus propagation}

Duck embryo fibroblasts (DEF) were prepared from 12-day-old SPF duck embryos (Harbin Veterinary Research Institute, Harbin, China) according to standard protocols. Cells were seeded at a density of $10^{6}$ cells $/ \mathrm{ml}$ in Dulbecco's Modified Eagle Medium (DMEM; GIBCO), supplemented with $10 \%$ fetal bovine serum (FBS; GIBCO), 100 units $/ \mathrm{ml}$ penicillin (GIBCO), and $100 \mathrm{mg} / \mathrm{ml}$ streptomycin (GIBCO), in an incubator at $37{ }^{\circ} \mathrm{C}$ and $5 \% \mathrm{CO}_{2}$. DTMUV virus AH-F10 is a virulent strain isolated during an outbreak in Anhui province, China in 2013.

\section{Suicidal DNA vaccine construction}

Total DTMUV RNA was extracted from a viral suspension using a TIANamp Viral Total Nucleic Acid Purification Kit (TIANGEN Biotech, Beijing, China), according to the manufacturer's instructions. First-strand complementary DNA (cDNA) was then synthesized using M-MLV reverse transcriptase (Promega, Madison, WI, USA) and 6-nt random primers (Promega), and the ORF of the $\mathrm{E}$ gene was amplified by reverse transcription (RT)-PCR using the following primers: 5'- CGGGATCCGCC ACCATGTTCAGCTGTCTGGGGATG C-3' and 5'-TC CCCCGGGGGCATTGACATTTACTGCCAG-3'. These primers were designed with $\mathrm{BamHI}$ and SmaI restriction enzyme sites (underlined) for cloning purposes, as well as a Kozak sequence (italics) to optimize target gene expression. PCR products were purified and subcloned into pSCA1, an SFV replicon-based vector. The composition of the resulting plasmid, referred to as pSCA1-E, was confirmed by PCR and sequencing analyses. The vector was maintained by transforming into competent Escherichia coli DH5 $\alpha$ cells, and purified using the Wizard Plus Maxiprep DNA Purification System (Promega). 


\section{Detection of E expression in DEF cells}

DEF cells were transfected with pSCA1-E using Lipofectamine 2000 reagent (Invitrogen), according to the manufacturer's instructions. Forty-eight hours post-transfection, the cells were subjected to immunofluorescence microscopy (IFA) and western blot analyses for evaluation of the expression of E protein. For IFA analysis, cell monolayers were cultured on cover slips and fixed by incubation with cold $100 \%$ acetone for $30 \mathrm{~min}$ at $-20{ }^{\circ} \mathrm{C}$. Slides were then incubated with rabbit anti-E polyclonal serum $(1: 1,000)$ at $37^{\circ} \mathrm{C}$ for $30 \mathrm{~min}$, followed by fluorescein-conjugated goat anti-rabbit antibodies (Beijing Zsbio, Beijing, China) at $37^{\circ} \mathrm{C}$ for $30 \mathrm{~min}$. Cells were visualized using a Leica fluorescence microscope (Olympus, Tokyo, Japan).

For western blot analyses, DEF cells were transfected with pSCA1-E, cultivated for $48 \mathrm{~h}$, and lysed by incubation with lysis buffer. Proteins were then separated by $10 \%$ sodium dodecyl sulphate polyacrylamide gel electrophoresis (SDS-PAGE) and transferred to nitrocellulose membranes (Bio-Rad, Hercules, CA, USA). Membranes were incubated with rabbit anti-DTMUV E protein polyclonal serum $(1: 1,000)$, followed by HRP-conjugated goat anti-rabbit IgG antibodies (Beijing Zsbio). Protein bands were visualized by 3, 3'-diaminobenzidine tetrahydrochloride staining (TIANGEN).

\section{Immunization of ducks and virus challenge}

Forty female specific-pathogen-free (SPF) Sheldrake ducklings (7-day-old, free of anti-DTMUV antibodies) were obtained from Harbin Veterinary Research Institute, China. The ducklings were randomly divided into four groups of 10 ducklings each, and housed in separate rooms. The animals were then immunized by intramuscular injection of $200 \mu \mathrm{g}$ pSCA1-E plasmid (pSCA1-E group), $200 \mu \mathrm{g}$ empty pSCA1 vector (pSCA1 group), $200 \mu \mathrm{l}$ commercially inactivated DTMUV vaccine (inactivated HB strain group, Rinpu, Tianjin, China) or $200 \mu \mathrm{l}$ PBS (negative control) into the quadriceps muscle. Immunization was carried out twice at 2-week intervals. Serum samples from the four groups were collected 0,1 , 2,3 , and 4 weeks post-primary immunization (ppi) for specific antibodies and neutralizing antibodies test. At 2 and 4 weeks after primary immunization, bloods were collected for lymphocyte proliferation assay and cytokines detection. Two weeks after the second immunization, ducklings were challenged with $10^{4.6}$ ELD $_{50}$ (embryo lethal dose) of DTMUV AH-F10 via intramuscular injection. Ducklings were observed daily for 2 weeks post-challenge.

\section{Antibody responses against DTMUV}

Serum samples from ducks were determined by an indirect ELISA test using the recombinant $E$ protein of DTMUV, produced in E. coli BL21 (DE3), as antigen.
The E protein was expressed in E. coli BL21 (DE3) using the PET 32a expression system (Novagen) and the product were purified by dialysis method. Ninety-six wells flat-bottomed plates (Corning Costar) were coated with recombinant $\mathrm{E}$ protein in $0.1 \mathrm{M}$ carbonate/bicarbonate buffer $\left(\mathrm{pH}\right.$ 9.6) and incubated overnight at $4{ }^{\circ} \mathrm{C}$. After blocking with 5\% BSA in PBS, plates were incubated with duplicate twofold serial dilutions of test sera for $1 \mathrm{~h}$ at $37{ }^{\circ} \mathrm{C}$. Rabbit anti-ducks IgG HRP (KPL) at a 1:2000 dilution was then added for $1 \mathrm{~h}$ at $37^{\circ} \mathrm{C}$, followed by the addition of the substrate $2 \mathrm{~mm}$ Sulfuric acid. Absorbance was determined at $450 \mathrm{~nm}$ using a Bio-Rad microtitre plate reader.

\section{Viral neutralization testing}

For detection of virus-neutralizing antibodies (VNAs) against DTMUV, primary duck embryonic fibroblasts (DEFs) prepared from 10-day-old duck eggs (DTMUV-free) were trypsinized, seeded in $75-\mathrm{cm} 2$ flasks, and cultivated in DMEM containing 10\% FBS, $2 \mathrm{mM}$ glutamine, $100 \mathrm{U} / \mathrm{ml}$ penicillin, and $100 \mu \mathrm{g} / \mathrm{ml}$ streptomycin at $37{ }^{\circ} \mathrm{C}$ with $5 \%$ $\mathrm{CO} 2$. Serum samples were then heat-inactivated at $56{ }^{\circ} \mathrm{C}$ for $30 \mathrm{~min}$, and serially diluted (with an initial 1:2 dilution) with culture medium in 96-well plates. Diluted serum samples were pre-incubated with 200 TCID50 (tissue culture infectious dose; infectious dose capable of killing $50 \%$ of cultivated cells) DTMUV at $37^{\circ} \mathrm{C}$ for $1 \mathrm{~h}$. Mixtures were then added to 96-well plates containing approximately 105 DEFs/well, and antibody titres were determined by monitoring CPE (cytopathic effect) over 6 days. Each sample was independently tested in triplicate.

\section{Lymphocyte proliferation assay}

To evaluate cellular immune responses induced by pSCA1-E, lymphocyte proliferation was evaluated in ducklings at 2 and 4 weeks post immunization. For these analyses, blood samples were collected from the jugular vein in blood collection tubes containing 3.8\% sodium citrate. Peripheral blood mononuclear cells (PBMCs) were then isolated by treatment with Ficoll-Paque Plus (Amersham Biosciences, Buckinghamshire, UK) for $20 \mathrm{~min}$ at $18{ }^{\circ} \mathrm{C}$, seeded (100 $\mu$ l volumes; approximately $10^{5}$ cells/well) in 96-well plates, and mixed with $100 \mu \mathrm{l}$ of medium supplemented with or without inactivated DTMUV. Concanavalin A ( $5 \mu \mathrm{g} / \mathrm{ml}$; Sigma, St. Louis, MO, USA) was used as a positive control. PBMC samples were prepared in triplicate. Proliferation was measured according to a standard protocol. Briefly, after incubation for $96 \mathrm{~h}, 20 \mu \mathrm{l}$ of 3-(4, 5-dimethylthylthiazol-2-yl)-5-(3-carboxymethoxyphenyl)-2 -(4-sulfophenyl)-2H tetrazolium (inner salt; Promega) was added to each well, and the cells were incubated for $4 \mathrm{~h}$, after which the optical density of each well was measured at $450 \mathrm{~nm}\left(\mathrm{OD}_{450}\right)$. The stimulation index (SI) was calculated as the ratio of the average $\mathrm{OD}_{450}$ of wells containing 
antigen-stimulated cells to that of wells containing cells treated with medium only.

\section{Cytokine assays}

To evaluate the serum levels of the helper T cell (Th) 1and Th2-type cytokines interferon (IFN)- $\gamma$ and interleukin (IL)-4, respectively, supernatants were collected from peripheral blood at week 1 and 2 after the first vaccination and week 1 and 2 after the second vaccination, and subjected to enzyme-linked immunosorbent assay (ELISA) analysis using Bio-Plex Pro kits (Bio-Rad), according to the manufacturer's instructions.

\section{Detection of viral RNA}

Total RNA was extracted from the samples (serum and liver) of ducks with RNAeasy (Qiagen, Germany), and used immediately for cDNA synthesis. cDNA synthesis was performed with SuperScript II reverse transcriptase (RT) (Invitrogen, USA). Then the viral load in the tissues of ducklings was detected using qRT-PCR assay. The primers were designed referring to the sequences of $\mathrm{E}$ gene of DTMUV AH-F10. The forward and reverse primers were 5' - ATGTTCAGCTGTCTGGGGATGC-3' and 5'-GGCA TTGACATTTACTGCCAG-3', respectively.

\section{Histopathological analysis of organs}

At 2 weeks post-challenge, all ducklings were bled and euthanized. Organs were collected and subjected to histopathological analysis. After dehydration, organ tissue blocks were embedded in paraffin and cut into $4-\mu \mathrm{m}$ thick sections. Sections were then stained with hematoxylin and eosin and observed under a microscope (Olympus Corporation, Tokyo, Japan).

\section{Statistical analysis}

Statistical analysis was performed by using SPSS 15.0 (SPSS, Chicago, IL, USA). All data were presented as the mean \pm standard deviation (SD). The comparison between data was calculated using Student's t-test (between two groups) and one-way ANOVA and Tukey's multiple comparison tests (between multiple groups). Differences were considered statistically significant when $P$ values $<0.05$. Survival curves were made using the Kaplan-Meier method, and analyzed with a Long-rank (Mantel-Cox) test.

\section{Results}

Expression of E glycoprotein in DEF cells

To test whether the constructed plasmid (pSCA1-E) could express E glycoprotein in vitro, DEF cells were transfected with individual plasmids and the expression of E glycoprotein was examined via IFA and western blot analyses. As expected, cells transfected with pSCA1-E exhibited a robust green fluorescence signal. In contrast, no fluorescence signal was observed in control cells transfected with pSCA1 empty plasmid (Fig. 1a). Meanwhile, western blot analysis detected a protein approximately $55 \mathrm{kDa}$ in size in the lysates of cells transfected with pSCA1-E, but not in those of the control cells (Fig. 1b). These data demonstrate that E glycoprotein can be highly expressed by pSCA1-E plasmid and retained its high immunoreactivity of the anti-E antibody in vitro.

\section{Humoral immune responses in ducklings immunized with pSCA1-E plasmid}

To evaluate the immunogenicity of the recombinant replicon plasmid pSCA1-E, it was inoculated into ducklings as described in Methods. Blood was collected at week 0, $1,2,3$ and 4 after the first vaccination to test for the

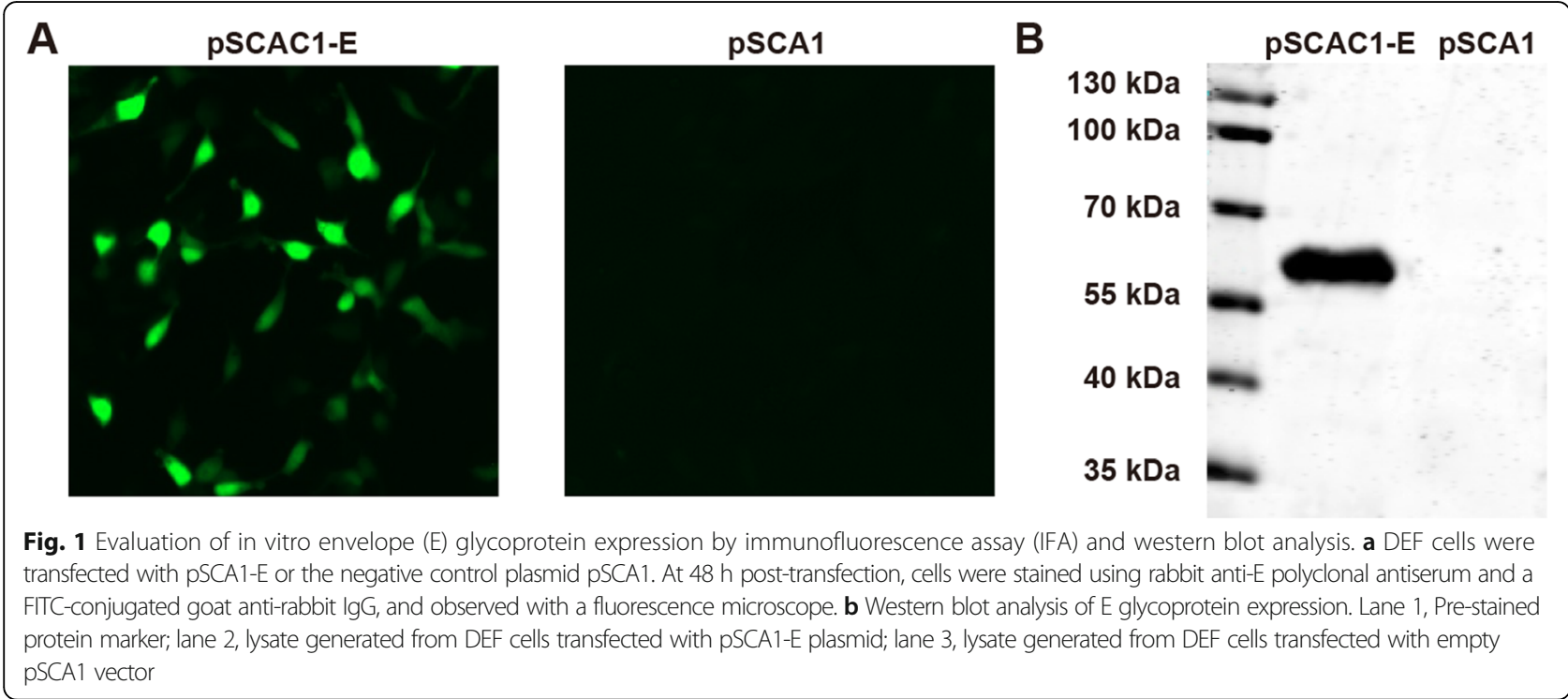



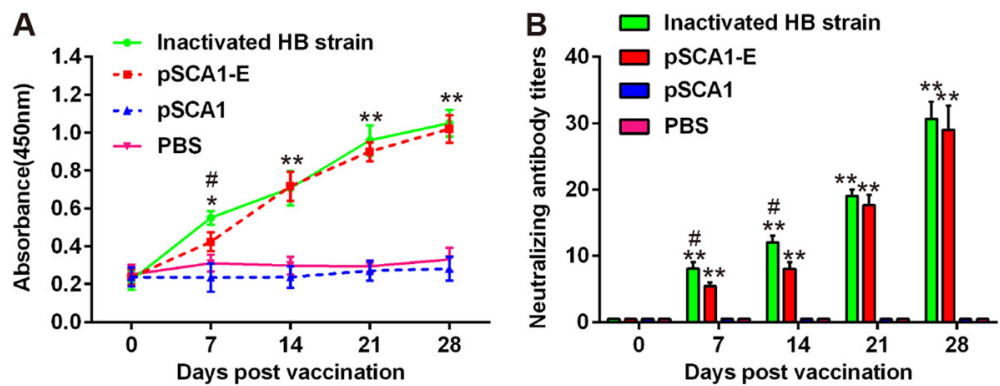

Fig. 2 Antibody levels in ducklings after immunization. a E glycoprotein-specific antibody levels were detected by indirect ELISA analysis. b Neutralization antibody levels were detected by serum neutralization assay. Each data represents the mean $\pm \mathrm{SD}$. ${ }^{*} P<0.05$, ${ }^{* *} P<0.01$ vs. PBS group; $\# P<0.05$ vs. inactivated HB strain group

presence of $\mathrm{E}$ glycoprotein-specific antibodies and neutralization antibodies. Specific anti-E antibody level was determined by an indirect ELISA. As shown in Fig. 2a, after the primary immunization, E glycoprotein-specific antibodies were detected in all ducklings immunized with pSCA1-E plasmid. After the booster immunization, the antibody level increased rapidly, and significantly higher than control groups (pSCA1 and PBS group). Meanwhile, the inactivated $\mathrm{HB}$ strain vaccine group also exhibited a high antibody level, whereas there was no significant difference between the pSCA1-E group and inactivated HB strain group. Next, a microneutralization assay was performed to evaluate the ability of serum samples to neutralized DTMUV virulent strain. As shown in Fig. 2b, all ducklings immunized with pSCA1-E plasmid and inactivated $\mathrm{HB}$ strain vaccine developed neutralizing antibodies after first immunization and reached peak level at 4 weeks. Conversely, detectable levels of neutralizing antibodies were not produced by any of the ducklings in the pSCA1 control and PBS negative control groups during the experiment.

\section{DTMUV-specific T cell proliferation}

To investigate cellular immunity responses induced by pSCA1-E plasmid, we analyzed the lymphocyte proliferative responses of all ducks at 2 and 4 weeks after the primary immunization. The results manifested that pSCA1-E and inactivated HB strain vaccine displayed obvious and intense lymphocyte proliferate responses (Fig. 3a). Notably, at 4 weeks, the values of pSCA1-E immunization group were higher than inactivated $\mathrm{HB}$ strain vaccine group, suggesting the robust cellular immune responses in PSCA1-E group.

\section{Cytokines induced by PSCA1-E immunization}

To further evaluate cellular immunity responses induced by pSCA1-E plasmid, serum IFN- $\gamma$ and IL-4 levels were assessed at 2 and 4 weeks after the primary immunization by ELISA analysis. As shown in Fig. $3 \mathrm{~b}$ and c, the mean levels of both cytokines were significantly higher in ducklings inoculated with pSCA1-E plasmid than in those treated with pSCA1 or PBS. These were no significant difference between pSCA1-E group and inactivated vaccine group.

\section{Protection against DTMUV challenge}

To determine whether the suicidal DNA vaccine could protect against infection by a virulent DTMUV strain, ducklings were challenged with DTMUV AH-FH10 at
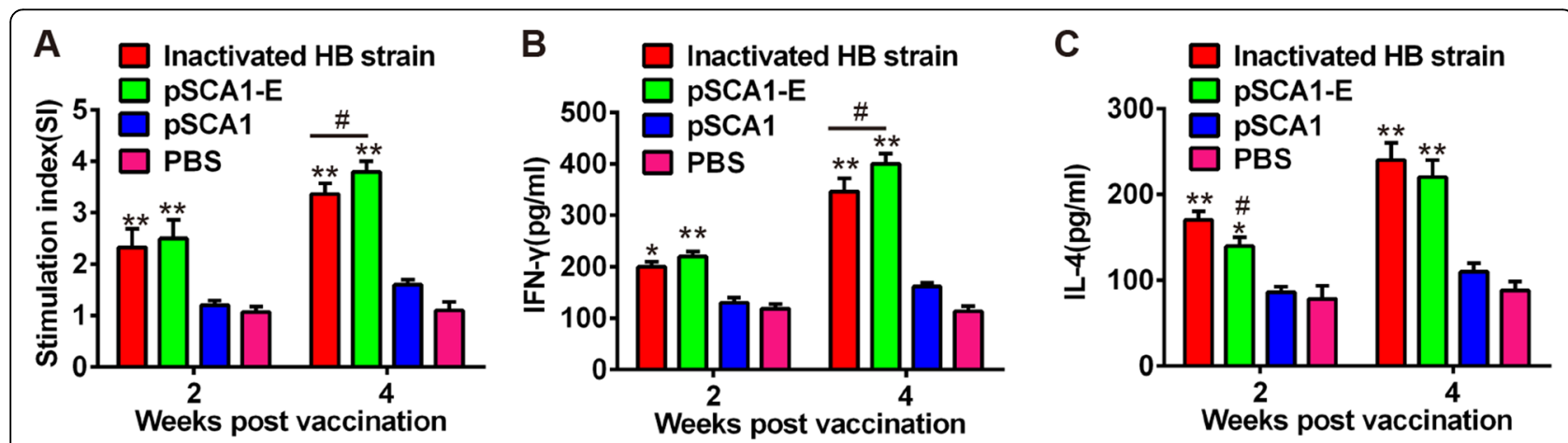

Fig. 3 Cellular immune response in ducklings immunized with pSCA1-E plasmid. a Specific proliferation of PBMCs in immunized ducks. The data are presented as the mean absorbance value of each group. $\mathbf{b}$ The interferon gamma (IFN- $\gamma$ ) concentration in serum from immunized ducklings was measure by ELISA. c The interleukin (IL-4) concentration in serum from immunized ducklings was measure by ELISA. Each data represents the mean $\pm S D$. ${ }^{*} P<0.05,{ }^{* *} P<0.01$ vs. PBS group; $\# P<0.05$ vs. inactivated HB strain group 


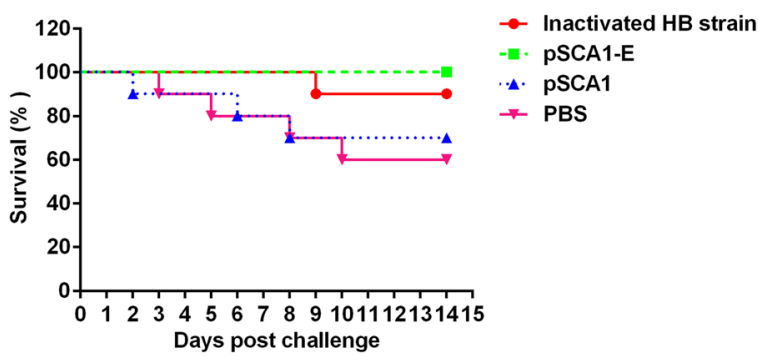

Fig. 4 The survival rate in ducklings after virulent DTMUV challenge. The statistical significance of differences in mortality between groups was determined using Kaplan-Meier method, and analyzed with a Log-rank (Mantel-Cox) test. For pSCA1-E group vs. PBS group, $P<0.05$; for inactivated HB strain group vs. PBS group, $P<0.05$; and for pSCA1-E group vs. inactivated HB strain group, $P>0.05$

2 weeks after the second immunization. All ducklings were housed in an isolation facility and examined for 2 weeks after the challenge. The ducklings from the pSCA1 and PBS control groups exhibited symptoms typical of DTMUV infections, including the manifestation of neurological signs, weight loss, and green-colored feces, beginning at 2 days post-viral challenge. As showed in Fig. 4, all of the ducklings were protected against challenge with virulent DTMUV in pSCA1-E group and 9 of 10 ducklings were protected in inactivated $\mathrm{HB}$ strain vaccine group. However, 3 and 4 of the 10 ducklings in pSCA1group and PBS group died respectively.

\section{Detection results of viral RNA in blood and organs}

In order to detect viral load in blood and organs of ducklings after the virus challenge, real-time qRT-PCR was performed using $E$ gene-specific primers. As expected, high viral copies were detected in blood (Fig. 5a), spleen (Fig. 5b), kidney (Fig. 5c), lung (Fig. 5d), brain (Fig. 5e) and liver (Fig. 5f) of all ducklings in pSCA1 and PBS group. However, only one or two ducklings were positive in pSCA1-E group and inactivated HB strain vaccine group. Importantly, the viral loads in these positive samples were also significantly lower than two control groups (Fig. 5a-f). These data indicated that vaccination with pSCA1-E

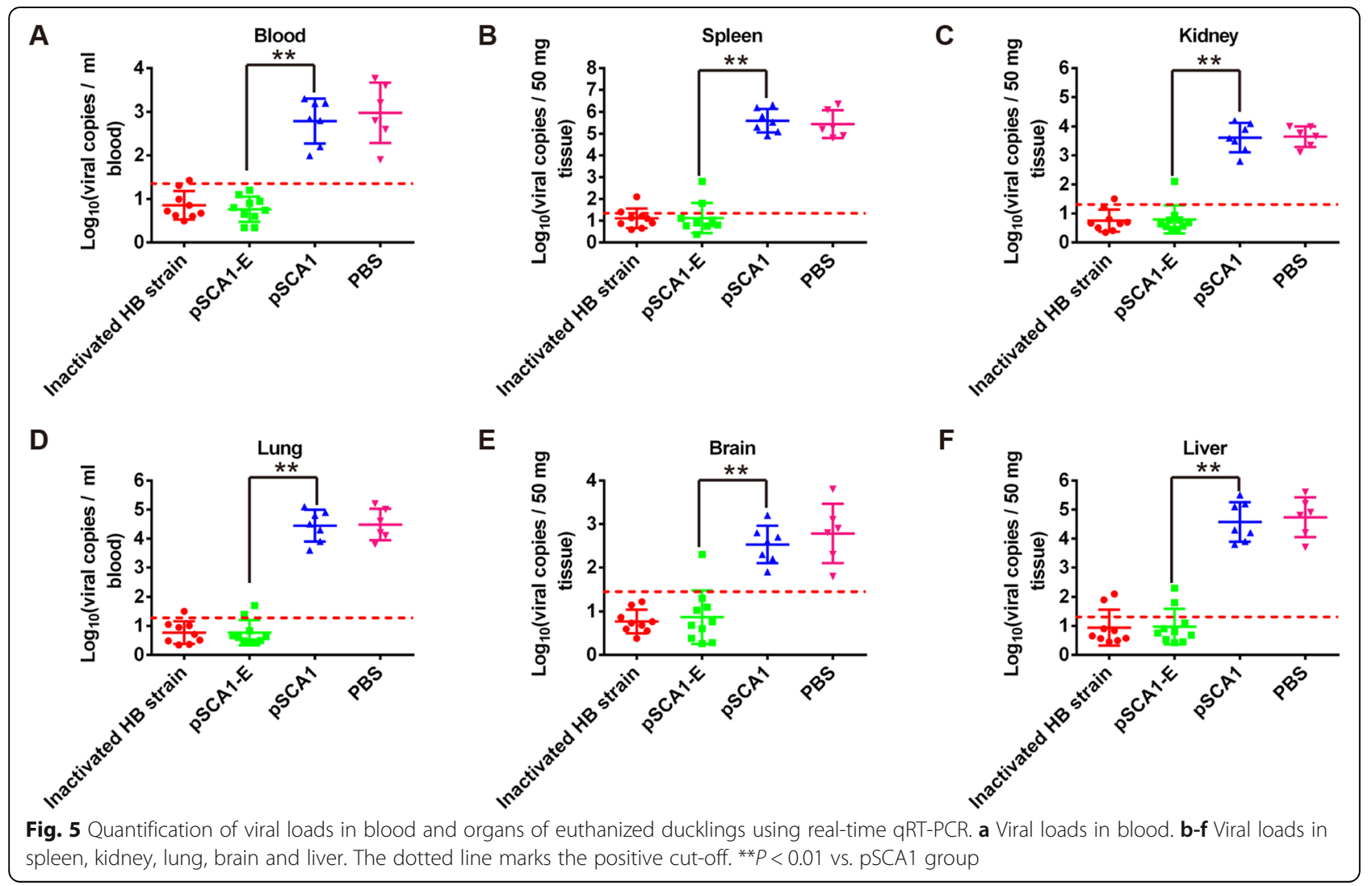




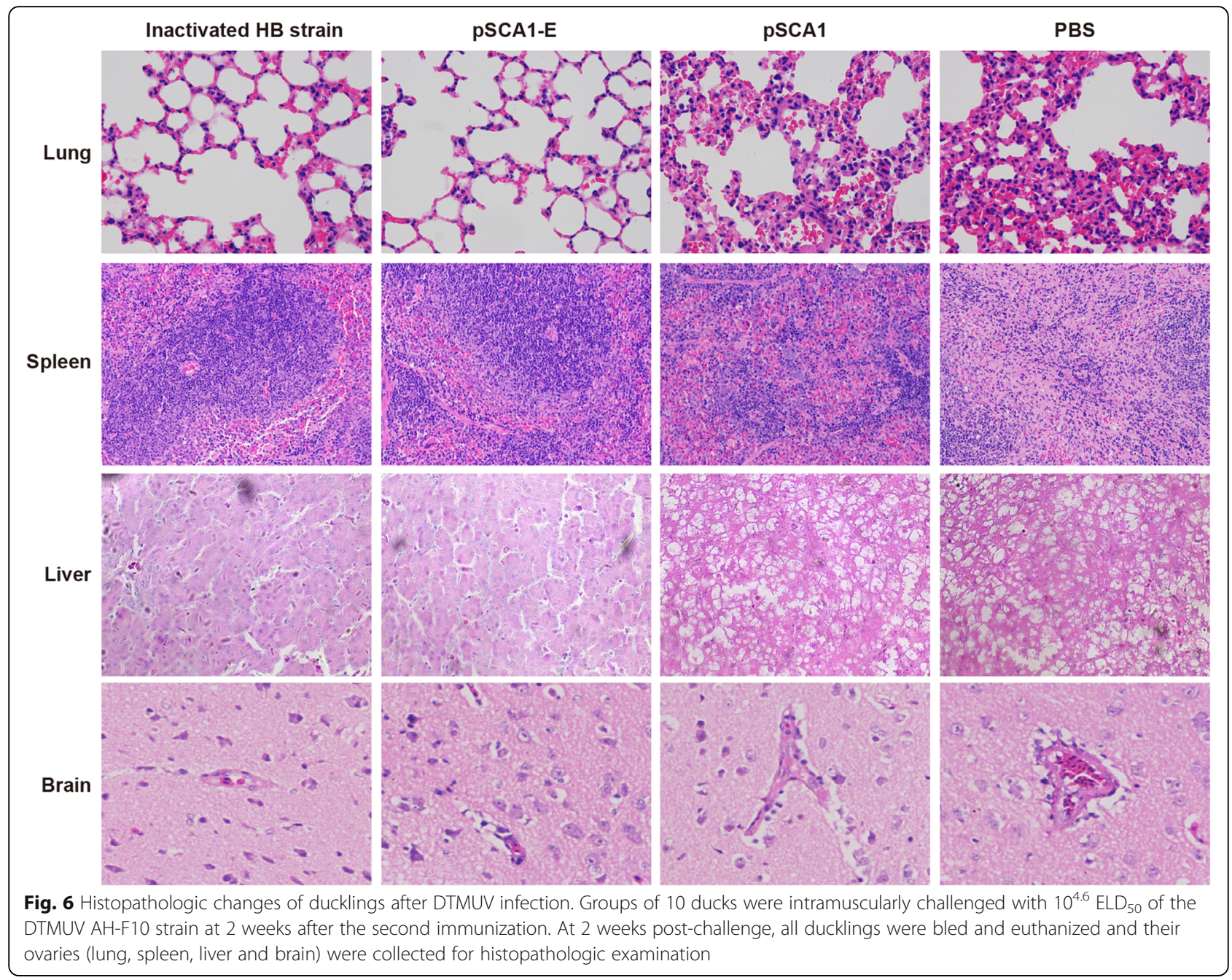

could significantly reduce the onset of viremia and decrease virus replication in ducklings.

\section{Histopathological assays of major target organs in DTMUV-infected ducklings}

To further understand the basis for the pSCA1-E vaccine protection of ducklings, we examined the histopathological changes of major target organs. As shown in Fig. 6, histopathological changes were observed in the organs of the ducklings in the non-immune groups (pSCA1 and PBS group) including interstitial pneumonia and pneummorrhagia in the lung, the number of lymphocytes in the white pulp decreased significantly and the boundaries between the red pulp and white pulp disappeared in the spleen, hepatocyte vacuolation and heterophilic granulocyte infiltrate in the liver and encephalitic lesions with severe perivascular inflammatory infiltrates in the brain. However, the organs of the ducklings in the two vaccinated groups showed no histologic lesions.

\section{Discussion}

The E glycoprotein of Flavivirus is the major antigen targeted by neutralizing antibodies, and several studies have shown that $\mathrm{E}$ protein-derived vaccines can protect animals against West Nile and Japanese encephalitis viruses $[39,40]$. In this study, we therefore generated a suicidal DNA vaccine expressing the E gene of DTMUV. IFA and western blot analyses demonstrated that the $\mathrm{E}$ protein was highly expressed in DEF cells, while immunization analyses suggested that the DNA vaccine induced strong humoral and cellular immune responses in ducklings. More importantly, this DNA vaccine conferred $100 \%$ protection against the virulent DTMUV challenge in ducklings. In any case, histopathological changes were observed in the organs of the ducklings in the non-immune groups including interstitial pneumonia and pneummorrhagia in the lung, the number of lymphocytes in the white pulp decreased significantly in the spleen, hepatocyte vacuolation in the liver and encephalitic lesions in the brain. Conversely, the organs of the ducklings inoculated with pSCA1-E appeared healthy 
and normal (data not shown). These findings indicate that the pSCA1-E vaccine provides well protection against DTMUV infection in ducklings.

It has become increasingly accepted that the IFN- $\gamma$ dependent Th1 cellular response is required for the protection against Flavivirus infection [41-43]. In this study, we also found the ducklings immunized with pSCA1-E exhibited distinct robust Th1 cellular immune responses than the negative control animals. This effect could be due to the production of double-stranded viral RNA-derived intermediates induced by the suicidal DNA vaccine, which have been shown to induce caspase-dependent apoptosis in transfected cells [44]. These apoptotic cells could then have been taken up by dendritic cells [45], which can act as an adjuvant for $\mathrm{T}$ cell-specific stimulation by the antigen [44]. The intensity of the host response to suicidal DNA vaccine typically corresponds to the serum levels of pro-inflammatory cytokines such as IFN- $\gamma$, which inhibits the viral replication. Meanwhile, ILs are known to mediate $\mathrm{T}$ and $\mathrm{B}$ lymphocyte activation, proliferation, and differentiation during immune activation and regulation [46, 47]. Our data demonstrated that the pSCA1-E vaccine also elicited a higher level of IL-4 in ducklings. These findings confirmed that pSCA1-E vaccine induces an enhanced Th1-type response and cell-mediated immune responses may play an important role in this DNA vaccine against DTMUV infection.

\section{Conclusion}

In conclusion, the pSCA1-E suicidal DNA vaccine induced strong humoral and cellular immune responses as well as completely resisted to DTMUV challenge in ducklings. These findings suggest that our suicidal DNA vaccine might comprise an effective prophylactic measure against DTMUV infection in ducklings. Further work is required to evaluate the protective effects of this DNA vaccine in field tests.

\footnotetext{
Abbreviations

C: Capsid protein; CDNA: Complementary DNA; CPE: Cytopathic effect; DIVA: Differentiating infected from vaccinated animals; DMEM: Dulbecco's Modified Eagle Medium; DTMUV: Duck Tembusu virus; E: Envelope glycoprotein; $E_{5 L}$ : 50\% embryo lethal dose; FBS: Fetal bovine serum; IFN- $\gamma$ : Interferon (IFN)- $\gamma$; NS: Nonstructural proteins; ORF: Open reading frame; prM: Pre-membrane; SDS-PAGE: Sulphate polyacrylamide gel electrophoresis; SFV: Semliki Forest virus; SPF: Specific-pathogen-free; VNAs: Virus-neutralizing antibodies
}

\section{Funding}

This study was supported by the key research project of national science and technology (No. 2016YFD0500805 and No. 2018YFD0500100), Key Project of Department of Science and Technology in Anhui province (No.11070303024), Key project of educational commission of Anhui province of China (No. KJ2012A124), and AnHui Province Key Laboratory of Veterinary Pathobiology and Disease Control (No. SYZD2017002). This study was supported by the key research project of national science and technology (2016YFD0500108), the Chinese Natural Sciences Foundation (31672572), the key project of Agriculture science and technology of Shanghai (2016043) and the Foundation of Shanghai Key Laboratory of Veterinary Biotechnology (klab201712).

\section{Availability of data and materials}

All data and materials are available in this manuscript.

\section{Authors' contributions}

Planned experiments: GL and GW; Performed experiments: JT, ZB, MD and DY; Analyzed data: ZB, JT, MD, DY, JZ, LZ, QM and YZ; Contributed reagents or other essential material: GL and GW; Wrote the paper: ZB and JT; Manuscript review: GL and GW. All authors read and approved the final manuscript.

\section{Ethics approval and consent to participate}

We confirmed that all animal experiments were carried out accordance with the guideline of the Guide for the Care and Use of Laboratory Animal of the Institutional Animal Care and Use Committee (IACUC) set by Anhui Agricultural University. All animal experiments were approved by the Animal Care and Use Committee of Anhui Agricultural University (Approval number AHAU2015-23).

\section{Consent for publication}

Not applicable.

\section{Competing interests}

The authors declare that they have no competing interests.

\section{Publisher's Note}

Springer Nature remains neutral with regard to jurisdictional claims in published maps and institutional affiliations.

\section{Author details}

${ }^{1}$ College of Animal Science and Technology, Anhui Agricultural University, Hefei 230036, China. ${ }^{2}$ Shanghai Veterinary Research Institute, Chinese Academy of Agricultural Sciences, No. 518 Ziyue Rd, Shanghai 200241, China. ${ }^{3}$ Anhui Province Key Laboratory of Veterinary Pathobiology and Disease Control, Hefei 230036, China.

Received: 14 February 2018 Accepted: 5 September 2018

Published online: 14 September 2018

\section{References}

1. Yan P, Zhao Y, Zhang X, Xu D, Dai X, Teng Q, Yan L, Zhou J, Ji X, Zhang S, et al. An infectious disease of ducks caused by a newly emerged Tembusu virus strain in mainland China. Virology. 2011;417:1-8.

2. Cao Z, Zhang C, Liu Y, Liu Y, Ye W, Han J, Ma G, Zhang D, Xu F, Gao X, et al. Tembusu virus in ducks, China. Emerg Infect Dis. 2011;17:1873-5.

3. Liu P, Lu H, Li S, Wu Y, Gao GF, Su J. Duck egg drop syndrome virus: an emerging Tembusu-related flavivirus in China. Sci China Life Sci. 2013;56: $701-10$

4. Li N, LV C, Yue R, Shi Y, Wei L, Chai T, Liu S. Effect of age on the pathogenesis of duck tembusu virus in Cherry Valley ducks. Front Microbiol. 2015;6:581.

5. Shen HQ, Lin WC, Wang ZX, Zhang K, Yan ZQ, Zhou QF, Qin JP, Xie QM, Bi $Y Z$, Chen F. Pathogenicity and genetic characterization of a duck Tembusu virus associated with egg-dropping in Muscovy ducks. Virus Res. 2016;223: 52-6.

6. Thontiravong A, Ninvilai P, Tunterak W, Nonthabenjawan N, Chaiyavong S, Angkabkingkaew K, Mungkundar C, Phuengpho W, Oraveerakul K, Amonsin A. Tembusu-related Flavivirus in ducks, Thailand. Emerg Infect Dis. 2015;21: 2164-7.

7. Homonnay ZG, Kovacs EW, Banyai K, Albert M, Feher E, Mato T, Tatar-Kis T, Palya V. Tembusu-like flavivirus (Perak virus) as the cause of neurological disease outbreaks in young Pekin ducks. Avian Pathol. 2014;43:552-60.

8. Yun T, Zhang D, Ma X, Cao Z, Chen L, Ni Z, Ye W, Yu B, Hua J, Zhang Y, Zhang $C$. Complete genome sequence of a novel flavivirus, duck tembusu virus, isolated from ducks and geese in China. J Virol. 2012;86:3406-7.

9. Liu M, Chen S, Chen Y, Liu C, Chen S, Yin X, Li G, Zhang Y. Adapted Tembusu-like virus in chickens and geese in China. J Clin Microbiol. 2012;50: 2807-9.

10. Tang Y, Diao Y, Yu C, Gao X, Ju X, Xue C, Liu X, Ge P, Qu J, Zhang D. Characterization of a Tembusu virus isolated from naturally infected house sparrows (Passer domesticus) in northern China. Transbound Emerg Dis. 2013;60:152-8. 
11. Tang Y, Gao X, Diao Y, Feng Q, Chen H, Liu X, Ge P, Yu C. Tembusu virus in human, China. Transbound Emerg Dis. 2013;60:193-6.

12. Li G, Gao X, Xiao Y, Liu S, Peng S, Li X, Shi Y, Zhang Y, Yu L, Wu X, et al. Development of a live attenuated vaccine candidate against duck Tembusu viral disease. Virology. 2014;450-451:233-42.

13. Nielsen HS, Oleksiewicz MB, Forsberg R, Stadejek T, Botner A, Storgaard T. Reversion of a live porcine reproductive and respiratory syndrome virus vaccine investigated by parallel mutations. J Gen Virol. 2001;82:1263-72.

14. Zhou B, Meliopoulos VA, Wang W, Lin X, Stucker KM, Halpin RA, Stockwell TB, Schultz-Cherry S, Wentworth DE. Reversion of cold-adapted live attenuated influenza vaccine into a pathogenic virus. J Virol. 2016;90:8454-63.

15. Schlesinger S. Alphavirus vectors: development and potential therapeutic applications. Expert Opin Biol Ther. 2001;1:177-91.

16. Sun C, Gardner CL, Watson AM, Ryman KD, Klimstra WB. Stable, high-level expression of reporter proteins from improved alphavirus expression vectors to track replication and dissemination during encephalitic and arthritogenic disease. J Virol. 2014;88:2035-46.

17. Quetglas J, Ruiz-Guillen M, Aranda A, Casales E, Bezunartea J, Smerdou C. Alphavirus vectors for cancer therapy. Virus Res. 2010;153:179-96.

18. Erdman MM, Kamrud Kl, Harris DL, Smith J. Alphavirus replicon particle vaccines developed for use in humans induce high levels of antibodies to influenza virus hemagglutinin in swine: proof of concept. Vaccine. 2010;28:594-6.

19. Wang Y, Liu G, Shi L, Li W, Li C, Chen Z, Jin H, Xu B, Li G. Immune responses in mice vaccinated with a suicidal DNA vaccine expressing the hemagglutinin glycoprotein from the peste des petits ruminants virus. J Virol Methods. 2013;193:525-30.

20. Jiang $Y$, Fang $L$, Xiao $S$, Li B, Pan $Y$, Luo $R$, Chen $H$. A suicidal DNA vaccine co-expressing two major membrane-associated proteins of porcine reproductive and respiratory syndrome virus antigens induce protective responses. Biotechnol Lett. 2009:31:509-18.

21. Yu X, Xiao S, Fang $L$, Jiang $Y, C$ Chen $H$. Enhanced immunogenicity to foodand-mouth disease virus in mice vaccination with alphaviral replicon-based DNA vaccine expressing the capsid precursor polypeptide (P1). Virus Genes. 2006:33:337-44

22. Li N, Zhao JJ, Zhao HP, Sun Y, Zhu QH, Tong GZ, Qiu HJ. Protection of pigs from lethal challenge by a DNA vaccine based on an alphavirus replicon expressing the E2 glycoprotein of classical swine fever virus. J Virol Methods. 2007;144:73-8

23. Berglund P, Smerdou C, Fleeton MN, Tubulekas I, Liljestrom P. Enhancing immune responses using suicidal DNA vaccines. Nat Biotechnol. 1998:16: 562-5.

24. Cheng Y, Chen Z, Li C, Meng C, Wu R, Liu G. Protective immune responses in rabbits induced by a suicidal DNA vaccine of the VP60 gene of rabbit hemorrhagic disease virus. Antivir Res. 2013;97:227-31.

25. Sun SQ, Liu XT, Guo HC, Yin SH, Shang YJ, Feng X, Liu ZX, Xie QG. Protective immune responses in Guinea pigs and swine induced by a suicidal DNA vaccine of the capsid gene of swine vesicular disease virus. J Gen Virol. 2007;88:842-8

26. Leitner WW, Hwang LN, deVeer MJ, Zhou A, Silverman RH, Williams BR, Dubensky TW, Ying H, Restifo NP. Alphavirus-based DNA vaccine breaks immunological tolerance by activating innate antiviral pathways. Nat Med. 2003;9:33-9.

27. Vander Veen RL, Harris DL, Kamrud Kl. Alphavirus replicon vaccines. Anim Health Res Rev. 2012;13:1-9.

28. Zheng L, Hu Y, Hua Q, Luo F, Xie G, Li X, Lin J, Wan Y, Ren S, Pan C, Tan F. Protective immune response in mice induced by a suicidal DNA vaccine encoding NTPase-II gene of toxoplasma gondii. Acta Trop. 2017;166:336-42.

29. Hsu KF, Hung CF, Cheng WF, He L, Slater LA, Ling M, Wu TC. Enhancement of suicidal DNA vaccine potency by linking Mycobacterium tuberculosis heat shock protein 70 to an antigen. Gene Ther. 2001:8:376-83.

30. Li L, An H, Sun M, Dong J, Yuan J, Hu Q. Identification and genomic analysis of two duck-origin Tembusu virus strains in southern China. Virus Genes. 2012;45:105-12.

31. Liu M, Liu C, Li G, Li X, Yin X, Chen Y, Zhang Y. Complete genomic sequence of duck flavivirus from China. J Virol. 2012:86:3398-9.

32. Roehrig JT. Antigenic structure of flavivirus proteins. Adv Virus Res. 2003;59: 141-75.

33. Despres P, Combredet C, Frenkiel MP, Lorin C, Brahic M, Tangy F. Live measles vaccine expressing the secreted form of the West Nile virus envelope glycoprotein protects against West Nile virus encephalitis. J Infect Dis. 2005;191:207-14
34. Xu XG, Wang ZS, Zhang Q, Li ZC, Zhao HN, Li W, Tong DW, Liu HJ. Baculovirus surface display of E envelope glycoprotein of Japanese encephalitis virus and its immunogenicity of the displayed proteins in mouse and swine models. Vaccine. 2011;29:636-43.

35. Aberle JH, Aberle SW, Allison SL, Stiasny K, Ecker M, Mandl CW, Berger R, Heinz FX. A DNA immunization model study with constructs expressing the tick-borne encephalitis virus envelope protein $E$ in different physical forms. J Immunol. 1999;163:6756-61.

36. Wang T, Anderson JF, Magnarelli LA, Wong SJ, Koski RA, Fikrig E. Immunization of mice against West Nile virus with recombinant envelope protein. J Immunol. 2001;167:5273-7.

37. Li Y, Ye J, Cao S, Xiao S, Zhao Q, Liu X, Jin M, Chen H. Immunization with pseudotype baculovirus expressing envelope protein of Japanese encephalitis virus elicits protective immunity in mice. J Gene Med. 2009;11:150-9.

38. Raviprakash K, Kochel TJ, Ewing D, Simmons M, Phillips I, Hayes CG, Porter KR. Immunogenicity of dengue virus type 1 DNA vaccines expressing truncated and full length envelope protein. Vaccine. 2000;18:2426-34.

39. Konishi E, Pincus S, Paoletti E, Shope RE, Burrage T, Mason PW. Mice immunized with a subviral particle containing the Japanese encephalitis virus $\mathrm{prM} / \mathrm{M}$ and $\mathrm{E}$ proteins are protected from lethal JEV infection. Virology. 1992;188:714-20.

40. Schneeweiss A, Chabierski S, Salomo M, Delaroque N, Al-Robaiy S, Grunwald T, Burki K, Liebert UG, Ulbert S. A DNA vaccine encoding the E protein of West Nile virus is protective and can be boosted by recombinant domain DIII. Vaccine. 2011;29:6352-7.

41. Singla M, Kar M, Sethi T, Kabra SK, Lodha R, Chandele A, Medigeshi GR. Immune response to dengue virus infection in pediatric patients in New Delhi, India--association of viremia, inflammatory mediators and monocytes with disease severity. PLoS Negl Trop Dis. 2016;10:e0004497.

42. Chen HW, Huang HW, Hu HM, Chung HH, Wu SH, Chong P, Tao MH, Pan CH. A poorly neutralizing IgG2a/c response elicited by a DNA vaccine protects mice against Japanese encephalitis virus. J Gen Virol. 2014;95:1983-90.

43. Chu JH, Chiang CC, Ng ML. Immunization of flavivirus West Nile recombinant envelope domain III protein induced specific immune response and protection against West Nile virus infection. J Immunol. 2007; 178:2699-705

44. Leitner WW, Ying H, Restifo NP. DNA and RNA-based vaccines: principles, progress and prospects. Vaccine. 1999;18:765-77.

45. Albert ML, Sauter B, Bhardwaj N. Dendritic cells acquire antigen from apoptotic cells and induce class I-restricted CTLs. Nature. 1998;392:86-9.

46. Lu B, Zhang B, Wang L, Ma C, Liu X, Zhao Y, Jiao Y. Hepatitis B virus e antigen regulates monocyte function and promotes $B$ lymphocyte activation. Viral Immunol. 2017;30:35-44.

47. Cantrell D. Signaling in lymphocyte activation. Cold Spring Harb Perspect Biol. 2015;7:a018788
Ready to submit your research? Choose BMC and benefit from:

- fast, convenient online submission

- thorough peer review by experienced researchers in your field

- rapid publication on acceptance

- support for research data, including large and complex data types

- gold Open Access which fosters wider collaboration and increased citations

- maximum visibility for your research: over $100 \mathrm{M}$ website views per year

At $\mathrm{BMC}$, research is always in progress.

Learn more biomedcentral.com/submission 